NEWS

\title{
Geoengineers get the fear
}

\section{Researchers fail to come up with clear guidelines for experiments that change the planet's climate.}

"Be very careful." The warning, from Robert Socolow, a climate researcher at Princeton University in New Jersey, came at the end of a meeting last week that aimed to thrash out guidelines for the nascent field of geoengineering. The discipline aims to use global-scale efforts to control the climate and mitigate the worst effects of anthropogenic warming - but the techniques used could also have far-reaching, unintended consequences.

Socolow presented more than 175 experts from a range of disciplines with a list of their own nightmares, collected over meals and cocktails during the course of an often contentious week. As he rattled through the scenarios, he highlighted the legal, moral and ethical quandaries of geoengineering.

In one, a single country unilaterally pumps aerosols into the stratosphere to block the Sun's rays and preserve - or perhaps create - a climate of its own liking. In another, climate policies result in a world full of forest plantations that are created solely to store the greatest possible amount of carbon, with no regard for preserving biodiversity. Or what if the very possibility of using geoengineering to mitigate climate change gives political leaders cover to say that greenhouse gases aren't a problem?

The morning after Socolow's sobering talk, the conference's scientific organizing committee released a summary statement, based on attendees' comments, that endorsed geoengineering research as a viable way of avoiding possibly catastrophic global warming. But participants came up short on their stated goal of formulating a set of guidelines and principles for scientists working in the field, and conference organizers promised further work on these in the coming weeks. Instead, it was Socolow's cautionary note that resonated as participants departed the beachside Asilomar Conference Center near Monterey, California. "We're scared, and nothing brings people together like fear," says Jane Long, associate director for energy and environment at Lawrence Livermore National Laboratory in California.

Organizers modelled the conference on a gathering at the same location 35 years ago, when eminent biologists established influential guidelines on experiments in the budding field

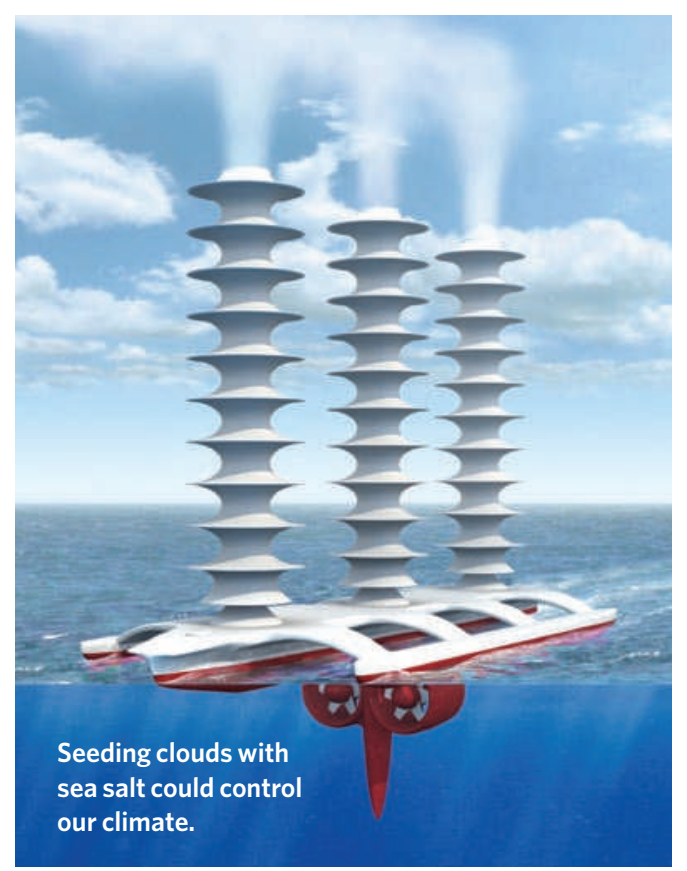

of genetic engineering. Despite disagreement on when - or indeed whether - the technologies should be used, says Long, participants generally agreed on the need to identify a responsible way forwards for geoengineering research. "It's a moral imperative to search for solutions," she adds. But it was evident from the beginning that the much broader field of geoengineering would not yield to simple principles as quickly as had genetics.

\section{Oranges, Porsches and whales}

The term geoengineering covers everything from mundane methods for increasing carbon storage in plants, soils and oceans to futuristic 'solar-radiation management' techniques - for example, creating haze in the stratosphere to act as a cheap layer of sunscreen. And that diverse definition is a problem, says David Keith, a

"We're scared, and nothing brings people together like fear." geoengineering researcher at the University of Calgary, Alberta. "People aren't discussing apples and oranges, they are talking about apples and oranges and Porsches and whales and moons," he says.

Testing solar-radiation management techniques on a global scale is particularly daunting, given that detecting changes in the climate system caused by geoengineering would be nearly as difficult as measuring global warming itself. It could take years to determine the main effects and decades to sort out any number of smaller impacts (see Nature 463, 426-427; 2010). Some fear that stratospheric aerosols could thin the ozone layer or shift global precipitation patterns.

Keith is developing a method to use aircraft to release fine sulphur particles that will stay aloft for years in the stratosphere. He says that there should be a way to conduct small-scale experiments that test this kind of technology without perturbing the global climate. But any larger experiments, in which the goal is to effect even small shifts in incoming solar energy at the global scale, should require authorization from a highlevel international body, he says.

Granger Morgan, an engineer at Carnegie Mellon University in Pittsburgh, Pennsylvania, proposed creating an assessment for field tests based on physical characteristics, such as experiment duration and the predicted reduction in warming. If researchers exceeded specified thresholds, international governance would have to authorize further experiments.

Another cadre of researchers is pushing a more benign technology that involves seeding clouds with sea salt to increase their brightness. This brightness could be turned on and off in a matter of days, because the clouds would disperse quickly once the seeding was stopped. The technique could be focused on regional problems such as disappearing Arctic sea ice, say advocates, who suggest that a research programme could be presented to the intergovernmental Arctic Council for approval.

"You can't build a wall around the Arctic climate," counters Alan Robock, a climatologist at Rutgers University in New Brunswick, New Jersey. He fears that some of his colleagues are pushing forwards too quickly in their hunt for a climate fix, although he was pleased with the conference's final statement.

The participants agreed that what's now needed is a broader discussion of geoengineering issues within civil society and government. In the meantime, other organizations, including the UK Royal Society and TWAS, the academy of sciences for the developing world, based in Trieste, Italy, are planning their own joint effort to face the fears about geoengineering - and find a way forwards.

Jeff Tollefson 